\title{
Papers
}

\section{How strong is the evidence for the use of perioperative $\beta$ blockers in non-cardiac surgery? Systematic review and meta-analysis of randomised controlled trials}

P J Devereaux, W Scott Beattie, Peter T-L Choi, Neal H Badner, Gordon H Guyatt, Juan C Villar, Claudio S Cinà, Kate Leslie, Michael J Jacka, Victor M Montori, Mohit Bhandari, Alvaro Avezum, Alexandre B Cavalcanti, Julian W Giles, Thomas Schricker, Homer Yang, Carl-Johan Jakobsen, Salim Yusuf

\begin{abstract}
Objective To determine the effect of perioperative $\beta$ blocker treatment in patients having non-cardiac surgery.

Design Systematic review and meta-analysis.

Data sources Seven search strategies, including searching two bibliographic databases and hand searching seven medical journals.

Study selection and outcomes We included randomised controlled trials that evaluated $\beta$ blocker treatment in patients having non-cardiac surgery. Perioperative outcomes within 30 days of surgery included total mortality, cardiovascular mortality, non-fatal myocardial infarction, non-fatal cardiac arrest, non-fatal stroke, congestive heart failure, hypotension needing treatment, bradycardia needing treatment, and bronchospasm.

Results Twenty two trials that randomised a total of 2437 patients met the eligibility criteria. Perioperative $\beta$ blockers did not show any statistically significant beneficial effects on any of the individual outcomes and the only nominally statistically significant beneficial relative risk was $0.44(95 \%$ confidence interval 0.20 to $0.97,99 \%$ confidence interval 0.16 to 1.24 ) for the composite outcome of cardiovascular mortality, non-fatal myocardial infarction, and non-fatal cardiac arrest. Methods adapted from formal interim monitoring boundaries applied to cumulative meta-analysis showed that the evidence failed, by a considerable degree, to meet standards for forgoing additional studies. The individual safety outcomes in patients treated with perioperative $\beta$ blockers showed a relative risk for bradycardia needing treatment of 2.27 (95\% CI 1.53 to $3.36,99 \%$ CI 1.36 to $3.80)$ and a nominally statistically significant relative risk for hypotension needing treatment of 1.27 (95\% CI 1.04 to 1.56 , 99\% CI 0.97 to 1.66 ).

Conclusion The evidence that perioperative $\beta$ blockers reduce major cardiovascular events is encouraging but too unreliable to allow definitive conclusions to be drawn.
\end{abstract}

\section{Introduction}

Non-cardiac surgery is associated with an increase in catecholamines, ${ }^{1}$ which results in an increase in blood pressure, heart rate, and free fatty acid concentrations. ${ }^{2-4} \beta$ blockers suppress the effects of increased catecholamines and as a result may prevent perioperative cardiovascular events.
Several authors and guideline committees have advocated the use of $\beta$ blockers for patients having non-cardiac surgery. ${ }^{5-8}$ The two authors of the American College of Physicians' non-cardiac surgery perioperative guidelines inserted an addendum, after the college had approved the guidelines, advocating the use of perioperative atenolol in patients with coronary artery disease. ${ }^{7}$ More recently, the American College of Cardiology/ American Heart Association task force on guidelines for non-cardiac surgery recommended perioperative $\beta$ blockers for patients with preoperative stress test ischaemia having vascular surgery (class I recommendation) and for patients with established coronary artery disease, risk factors for coronary artery disease, or untreated hypertension having non-cardiac surgery (class III recommendation). ${ }^{8}$ Other authors have questioned the robustness of the evidence for perioperative $\beta$ blockers and have advocated the need for a large definitive randomised controlled trial. ${ }^{9}{ }^{10}$

Accurate understanding of the strength of the evidence for perioperative $\beta$ blockers requires a systematic, comprehensive, and unbiased accumulation of the available evidence and methods adapted from formal interim monitoring boundaries applied to cumulative meta-analysis. ${ }^{11}$ We therefore undertook a systematic review and meta-analysis to evaluate the effect of $\beta$ blockers on cardiovascular events in patients having non-cardiac surgery.

\section{Methods}

\section{Eligibility criteria}

We included randomised controlled trials that evaluated the effect of $\beta$ blocker treatment in patients having non-cardiac surgery. Randomised controlled trials were eligible regardless of their publication status, language, or primary objectives. We excluded trials in which no control group received a placebo or standard care and those in which no relevant events occurred in the treatment and control groups, as these trials provide no information on the magnitude of treatment effects. ${ }^{12}$

\section{Study identification}

Strategies to identify studies included an electronic search of two bibliographical databases (see appendix A on bmj.com); a hand search of seven anaesthesia journals (appendix A); consultation 
with experts; our own files; review of reference lists from eligible trials; use of the "see related articles" feature for key publications in PubMed (April 2003); and search of SciSearch (April 2003) for publications that cited key publications.

\section{Assessment of study eligibility}

Two researchers independently evaluated study eligibility $(\kappa=0.96)$. The consensus process to resolve disagreements required researchers to discuss the reasoning for their decisions; in all cases, one person recognised an error.

\section{Data collection and quality assessment}

We abstracted descriptive data (such as type of surgery, patient population) and markers of validity (such as concealment, blinding) from all trials. We abstracted data on the following perioperative outcomes: total mortality, cardiovascular mortality, non-fatal myocardial infarction, non-fatal cardiac arrest, non-fatal stroke, congestive heart failure, hypotension needing treatment, bradycardia needing treatment, bronchospasm, and the composite outcome of major perioperative cardiovascular events (cardiovascular death, non-fatal myocardial infarction, or non-fatal cardiac arrest). We defined perioperative outcomes as outcomes that occurred within 30 days of surgery.

The definitions of outcomes were those used in the original trials, except when a trial did not define or report one of our main outcomes. We anticipated that three of our main outcomes would not be defined or reported in all trials. We therefore defined, a priori, cardiovascular death, bradycardia needing treatment, and hypotension needing treatment (see appendix B on bmj.com).

Teams of two researchers independently abstracted data from all trials $(\kappa=0.69-1.0)$. Disagreements were resolved by consensus according to the process described above.

\section{Statistical analysis}

For each trial we calculated the relative risks of the outcomes for patients receiving perioperative $\beta$ blocker treatment compared with patients receiving placebo or standard care. For each relative risk we determined the conventional 95\% confidence limit and the 99\% confidence limit. When (as with small trials with few or a moderate number of events) statistical significance depends on a difference of only a handful of events, the $99 \%$ confidence interval may better convey our confidence in the estimate of the treatment effect.

We did analyses on an intention to treat basis. We pooled relative risks by using the DerSimonian and Laird random effects model. ${ }^{13}$ We calculated an $\mathrm{I}^{2}$ value as a measure of heterogeneity for each outcome analysis. An $\mathrm{I}^{2}$ value represents the percentage of total variation across trials that is due to heterogeneity rather than to chance, and we considered $\mathrm{I}^{2}<25 \%$ as low and $\mathrm{I}^{2}>75 \%$ as high. ${ }^{14}$ Before the analyses we specified several hypotheses related to the markers of trial validity, treatment interventions, and duration of follow-up to explain potential heterogeneity $\left(\mathrm{I}^{2}>25 \%\right)$. We entered data in duplicate and used RevMan 4.2 (Cochrane Collaboration, Oxford) for all analyses.

Because no reason exists why the standards for a meta-analysis should be less rigorous than those for a good single randomised controlled trial, we used methods adapted from formal interim monitoring boundaries applied to cumulative meta-analysis to assess the reliability and conclusiveness of the available evidence on perioperative $\beta$ blockers,${ }^{15}$ focusing on the composite outcome of major perioperative cardiovascular events. The sample size needed for a reliable and conclusive meta-analysis is at least as large as that for a single optimally powered randomised controlled trial, so we calculated the sample size (optimal information size) requirement for our meta-analysis. We did formal interim monitoring for metaanalyses by using the optimal information size to help to construct a Lan DeMets sequential monitoring boundary for our meta-analysis, ${ }^{15}$ analogous to interim monitoring in a randomised controlled trial. We used this monitoring boundary as a way of determining whether the evidence in our meta-analysis was reliable and conclusive.

\section{Results}

\section{Included trials}

We identified 22 randomised controlled trials published between 1980 and 2004 that fulfilled our eligibility criteria (fig 1) ${ }^{16-37}$ We obtained data from or confirmed them with trialists from all included trials. Table 1 summarises the design characteristics of the included trials. ${ }^{16-37}$ The 22 trials randomised a total of 2437 patients, and the median sample size was 61 patients. The type of non-cardiac surgery was unrestricted in eight trials. Treatment interventions varied from brief intravenous $\beta$ blocker just before surgery to 30 day postoperative $\beta$ blocker use. The duration of follow-up was limited to the end of surgery in one trial and until discharge from the recovery room in five trials.

\section{Quality assessment}

Most randomised controlled trials fulfilled our quality measures (for example, all trials had complete patient follow-up). Table 2 reports the quality measures of the trials that failed to fulfil at least one of our markers of validity. ${ }^{192} 333536$

\section{Effect of perioperative $\beta$ blockers}

Table 3 presents the results of the meta-analyses. Overall only a moderate number of major perioperative cardiovascular events occurred (18 cardiovascular deaths, 58 non-fatal myocardial infarctions, and 7 non-fatal cardiac arrests).

Perioperative $\beta$ blockers did not show any statistically significant beneficial effects on any of the individual outcomes. Patients in four trials had fatal events. ${ }^{31-33}{ }^{37}$ Nine deaths (five cardiovascular) occurred among the 453 patients randomised to $\beta$ blocker treatment, compared with 19 deaths (13 cardiovascular) among the 454 patients randomised to placebo or standard care (relative risk $0.56,95 \%$ confidence interval 0.14 to $2.31,99 \%$ confidence interval 0.09 to 3.60 for total mortality; $0.40,0.14$ to $1.15,0.10$ to 1.60 for cardiovascular mortality).

The individual safety outcomes in patients treated with perioperative $\beta$ blockers showed a relative risk of 2.27 (1.53 to 3.36 , 1.36 to 3.80 ) for bradycardia needing treatment (fig 2) and 1.27 (1.04 to $1.56,0.97$ to 1.66 ) for hypotension needing treatment. Both these analyses showed low heterogeneity ( $\mathrm{I}^{2}$ of $3 \%$ for bradycardia needing treatment and $6 \%$ for hypotension needing treatment).

Eight trials had patients who had a major perioperative cardiovascular event (cardiovascular death, non-fatal myocardial infarction, or non-fatal cardiac arrest) (fig 3). ${ }^{30-37}$ Twenty eight major perioperative cardiovascular events occurred among the 589 patients randomised to $\beta$ blocker treatment, compared with 55 among the 563 patients randomised to placebo or standard care (relative risk $0.44,0.20$ to $0.97,0.16$ to 1.24 ). Moderate heterogeneity existed across the trial results $\left(\mathrm{I}^{2}=42 \%\right)$.

\section{Exploring heterogeneity}

Our a priori hypothesis related to trial validity helped to explain the heterogeneity. The three trials by Poldermans, Zaug, and Urban did not fulfil all our quality measures (these trials were stopped early after an interim analysis suggested a much larger 
Table 1 Design characteristics of randomised controlled trials included in systematic review

\begin{tabular}{lll} 
Trials & Year of publication & No randomised \\
\hline Coleman $^{16}$ & 1980 & 42 \\
\hline Cucchiara $^{17}$ & & 74
\end{tabular}

\section{Type of surgery and patient} population

patient elective general non-cardiac surgery

Inpatient carotid endarterectomy; patients with an $\mathrm{MI}$ in the preceding six months and CHF were excluded

\begin{tabular}{lccc}
\hline Jakobsen $^{18}$ & 1986 & 20 & \\
& & & \\
\hline Liu $^{19}$ & 1986 & 30 & Cxch
\end{tabular}

Inpatient middle ear or nasal septum surgery; patients with evidence of cardiopulmonary disease were excluded

Non-cardiac surgery (primarily gynaecological); unclear if restricted ASA class I

\begin{tabular}{|c|c|c|c|}
\hline Magnusson $^{20}$ & 1986 & 30 & $\begin{array}{l}\text { Inpatient cholecystectomy or hernia } \\
\text { repair; patients had untreated } \\
\text { hypertension but no prior MI or CHF }\end{array}$ \\
\hline
\end{tabular}

\begin{tabular}{lll}
\hline Gibson $^{21}$ & 4088 & Inpatient neurosurgery; patients had \\
& \\
& $\begin{array}{l}\geq 20 \% \text { increase in systolic blood } \\
\text { pressure above ward pressure on } \\
\text { emergence from anaesthesia }\end{array}$
\end{tabular}

\begin{tabular}{|c|c|c|c|}
\hline Stone $^{22}$ & 1988 & 128 & $\begin{array}{l}\text { Inpatient major non-cardiac surgery; } \\
\text { patients had untreated hypertension } \\
\text { but no CAD or CHF }\end{array}$ \\
\hline Mackenzie $^{23}$ & 1989 & 100 & $\begin{array}{l}\text { Outpatient gynaecological surgery or } \\
\text { dental extractions }\end{array}$ \\
\hline $\operatorname{lnada}^{24}$ & 1989 & 30 & $\begin{array}{l}\text { Inpatient elective non-cardiac surgery; } \\
\text { patients with CHF, unstable angina, or } \\
\text { ASA class IV were excluded }\end{array}$ \\
\hline Leslie $^{25}$ & 1989 & 60 & $\begin{array}{l}\text { Inpatient elective non-cardiac surgery; } \\
\text { patients were ASA class I or II but no } \\
\text { prior MI or CHF }\end{array}$ \\
\hline Jakobsen $^{26}$ & 1990 & 98 & $\begin{array}{l}\text { Inpatient elective hysterectomy or } \\
\text { lower extremity orthopaedic surgery; } \\
\text { patients were ASA class I or II }\end{array}$ \\
\hline Miller $^{27}$ & 1990 & 45 & $\begin{array}{l}\text { Inpatient elective peripheral vascular } \\
\text { surgery; patients had known CAD or } \\
\geq 2 \text { risk factors but no history of CHF } \\
\text { or MI within six months of surgery }\end{array}$ \\
\hline Miller $^{28}$ & 1991 & 548 & $\begin{array}{l}\text { Inpatient elective non-cardiac surgery; } \\
\text { patients had no history of CHF or MI } \\
\text { within six months of surgery }\end{array}$ \\
\hline Davies $^{29}$ & 1992 & 40 & Inpatient carotid endarterectomy \\
\hline Jakobsen $^{30}$ & 1997 & 36 & $\begin{array}{l}\text { Inpatient elective thoracotomy for lung } \\
\text { resection; patients without } \\
\text { cardiovascular problems }\end{array}$ \\
\hline Wallace $^{31}$ & 1998 & 200 & $\begin{array}{l}\text { Inpatient elective non-cardiac surgery; } \\
\text { patients with or at risk for CAD }\end{array}$ \\
\hline
\end{tabular}
to inpatient surgery; patients were

\section{Intervention}

Length of follow-up

Metoprolol $2 \mathrm{mg}$ or $4 \mathrm{mg}$, or placebo Discharge from hospital injection just before anaesthesia

Esmolol $500 \mu \mathrm{g} / \mathrm{kg} / \mathrm{min}$ for 4 minutes End of surgery

then $300 \mu \mathrm{g} / \mathrm{kg} / \mathrm{min}$ for 8 minutes or

placebo infusion starting 5 minutes

before anaesthesia

Oral metoprolol $50 \mathrm{mg}$ or placebo the Discharge from recovery room day before surgery and metoprolol

$100 \mathrm{mg}$ or placebo 1.5-3 hours before anaesthesia

Esmolol $500 \mu \mathrm{g} / \mathrm{kg} / \mathrm{min}$ for 4 minutes Discharge from recovery room then $300 \mu \mathrm{g} / \mathrm{kg} / \mathrm{min}$ for 8 minutes or placebo infusion starting 5 minutes before anaesthesia

Oral metoprolol $200 \mathrm{mg}$ or placebo Discharge from hospital daily for at least 2 weeks before surgery and the morning of surgery, and metoprolol $15 \mathrm{mg}$ or placebo injection just before anaesthesia

Esmolol $40 \mathrm{mg} / \mathrm{min}$ or placebo infusion for 4 minutes just before extubation and then esmolol 24 $\mathrm{mg} / \mathrm{min}$ or placebo infusion for 10 minutes

Oral labetalol $100 \mathrm{mg}$, atenolol $50 \mathrm{mg}$, Discharge from hospital oxprenolol $20 \mathrm{mg}$, or usual care 2 hours before surgery

Oral timolol $10 \mathrm{mg}$ or placebo 72 Discharge from hospital minutes before anaesthesia

Labetalol $5 \mathrm{mg}$ or $10 \mathrm{mg}$ or placebo

injection 2 minutes before anaesthesia

Labetalol $0.25,0.5,0.75$, or $1 \mathrm{mg} / \mathrm{kg} \quad$ Discharge from hospital

or placebo injection just before

surgery

Oral metoprolol (slow release) $100 \mathrm{mg}$ Discharge from hospital or placebo 1-3 hours before surgery

Esmolol $1.5 \mathrm{mg} / \mathrm{kg}$ or $3.0 \mathrm{mg} / \mathrm{kg}$ or $\quad$ Discharge from hospital placebo injection just before

anaesthesia

Esmolol $100 \mathrm{mg}$ or $200 \mathrm{mg}$ or

Discharge from recovery room

placebo injection just before

anaesthesia

Oral atenolol $50 \mathrm{mg}$ or placebo $2 \quad$ Day 4 post-surgery hours before surgery

Oral metoprolol $100 \mathrm{mg}$ or placebo 90 Day 11 post-surgery or minutes before surgery and once daily discharge from hospital if thereafter until day 11 post-surgery or sooner discharge from hospital if sooner Atenolol $5 \mathrm{mg}$ (for $\mathrm{HR} \geq 55 \mathrm{bpm}$ and Discharge from hospital $\mathrm{SBP} \geq 100 \mathrm{~mm} \mathrm{Hg}$ ) or placebo injection twice 30 minutes before surgery with repeat dosing immediately after surgery; daily thereafter the study drug was given the same way twice a day, or oral atenolol $100 \mathrm{mg}$ (for $\mathrm{HR}>65 \mathrm{bpm}$ and $\mathrm{SBP} \geq 100 \mathrm{~mm} \mathrm{Hg}$ ) or $50 \mathrm{mg}$ (for HR 55-65 bpm and $S B P \geq 100 \mathrm{~mm} \mathrm{Hg}$ ) or placebo on the first postoperative morning and each day until day 7 post-surgery or discharge from hospital if sooner

\begin{tabular}{|c|c|c|c|c|c|}
\hline & & & & & \\
\hline$\overline{\text { Bayliff }}{ }^{32}$ & 1999 & 99 & $\begin{array}{l}\text { Inpatient major (non-cardiac) thoracic } \\
\text { surgery }\end{array}$ & $\begin{array}{l}\text { Oral propranolol } 10 \mathrm{mg} \text { or placebo } \\
\text { every } 6 \text { hours, starting before surgery } \\
\text { and continuing for } 5 \text { days } \\
\text { post-surgery }\end{array}$ & Discharge from hospita \\
\hline Poldermans ${ }^{33}$ & 1999 & 112 & $\begin{array}{l}\text { Inpatient elective abdominal aortic or } \\
\text { infrainguinal arterial surgery; patients } \\
\text { had a cardiac risk factor and a } \\
\text { positive dobutamine echocardiography } \\
\text { study }\end{array}$ & $\begin{array}{l}\text { Oral bisoprolol } 5 \mathrm{mg} \text { daily for a least } \\
\text { a week before surgery and then } 10 \\
\mathrm{mg} \text { daily if } \mathrm{HR}>60 \mathrm{bpm} \text {; post-surgery } \\
\text { the study drug was continued for } 30 \\
\text { days; patients unable to take drugs } \\
\text { orally were given metoprolol infusions } \\
\text { to keep HR below } 80 \mathrm{bpm} \text {; control } \\
\text { group received standard perioperative } \\
\text { care }\end{array}$ & Day 30 post-surgery \\
\hline
\end{tabular}




\begin{tabular}{|c|c|c|c|c|c|}
\hline Trials & Year of publication & No randomised & $\begin{array}{l}\text { Type of surgery and patient } \\
\text { population }\end{array}$ & Intervention & Length of follow-up \\
\hline$\overline{R a b y^{34}}$ & 1999 & 26 & $\begin{array}{l}\text { Inpatient elective vascular surgery; } \\
\text { patients had ischaemia during } \\
\text { preoperative Holter monitor testing }\end{array}$ & $\begin{array}{l}\text { Esmolol or placebo infusion adjusted } \\
\text { every hour to reduce HR below a } \\
\text { predetermined ischaemic threshold } \\
\text { starting immediately post-surgery and } \\
\text { continuing for } 48 \text { hours }\end{array}$ & Hour 49 post-surgery \\
\hline Zaugg $^{35}$ & 1999 & 63 & $\begin{array}{l}\text { Inpatient elective major non-cardiac } \\
\text { surgery; patients with CHF were } \\
\text { excluded }\end{array}$ & $\begin{array}{l}\text { Group } 1-\text { control group received } \\
\text { standard perioperative care. Group } \\
2 \text {-atenolol } 5 \mathrm{mg} \text { (for HR>54 bpm } \\
\text { and } \mathrm{SBP}>99 \mathrm{~mm} \mathrm{Hg} \text { ) injection twice } \\
30 \text { minutes before surgery, repeat } \\
\text { dosing immediately after surgery, and } \\
\text { twice daily thereafter for } 72 \text { hours. } \\
\text { Group } 3 \text {-atenolol } 5 \mathrm{mg} \text { injections } \\
\text { every } 5 \text { minutes during surgery to } \\
\text { maintain HR<80 bpm and MAP } \leq 20 \% \\
\text { of preoperative MAP }\end{array}$ & Discharge from hospital \\
\hline $\operatorname{Urban}^{36}$ & 2000 & 120 & $\begin{array}{l}\text { Inpatient elective total knee } \\
\text { arthroplasty; patients had known or } \\
\text { probably CAD }\end{array}$ & $\begin{array}{l}\text { Esmolol infusion started within first } \\
\text { hour after surgery and titrated to keep } \\
\text { HR<80 bpm until next morning, then } \\
\text { metoprolol } 25 \mathrm{mg} \text { twice daily with } \\
\text { titration to keep HR<80 bpm; study } \\
\text { drug continued until discharge from } \\
\text { hospital; control group received } \\
\text { standard perioperative care }\end{array}$ & Discharge from hospital \\
\hline Yang ${ }^{37}$ & 2004 & 496 & $\begin{array}{l}\text { Inpatient elective vascular surgery } \\
\text { (abdominal aortic, infrainguinal, or } \\
\text { extra-anatomical); patients were ASA } \\
\text { III or less and had no history of CHF }\end{array}$ & $\begin{array}{l}\text { Oral metoprolol (50 mg for weight } \\
<75 \mathrm{~kg} \text { or } 100 \mathrm{mg} \text { for weight } \geq 75 \mathrm{~kg} \text { ) } \\
\text { or placebo } 2 \text { hours before surgery; } \\
\text { repeat dosing } 2 \text { hours after surgery; } \\
\text { daily thereafter the study drug was } \\
\text { given the same way twice a day until } \\
\text { day } 5 \text { post-surgery or discharge from } \\
\text { hospital if sooner; patients unable to } \\
\text { take drugs orally were given } \\
\text { metoprolol infusions of } 0.2 \mathrm{mg} / \mathrm{kg} \text { ( } 15 \\
\text { mg maximum) or placebo every } 6 \\
\text { hours }\end{array}$ & Day 30 post-surgery \\
\hline
\end{tabular}

ASA=American Surgical Association classification; bpm=beats per minute; $C A D=$ coronary artery disease; $C H F=$ congestive heart failure; HR=heart rate; $M A P=m e a n$ arterial pressure; $M \mathrm{I}=$ myocardial infarction; SBP=systolic blood pressure.

than predicted treatment effect or there was no blinding of patients, healthcare providers, or data collectors) and their pooled relative risk for major perioperative cardiovascular events was $0.13(0.04$ to $0.38,0.03$ to 0.54$)$ with $\mathrm{I}^{2}=0 \% .^{33}{ }^{35}$ The

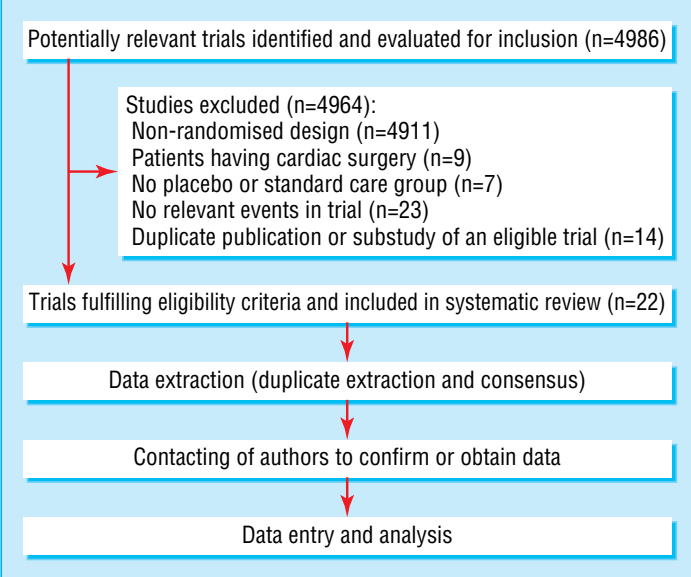

remaining five high quality trials had a pooled relative risk for major perioperative cardiovascular events of 0.82 (0.49 to 1.36 , 0.42 to 1.59 ) with $\mathrm{I}^{2}=0 \% .30-323437$

Reliability and conclusiveness of composite outcome result To determine the optimal information size we assumed a $10 \%$ control event rate (the control event rate in our meta-analysis for the composite outcome) and a 25\% relative risk reduction (the average relative risk reduction among the $\beta$ blocker myocardial infarction trials ${ }^{38}$ ) with $80 \%$ power and a 0.01 two sided $\alpha$. Our calculations indicated that the optimal information size needed to reliably detect a plausible treatment effect, for the composite outcome of major perioperative cardiovascular events, is 6124 patients. Currently, 1152 patients have been randomised in the $\beta$ blocker randomised controlled trials with patients who have had a major perioperative cardiovascular event. We used the optimal information size to help to construct the Lan-DeMets sequential monitoring boundary (fig 4). The sequential monitoring boundary has not been crossed, indicating that the cumulative evidence is unreliable and inconclusive.

Fig 1 Flowchart of randomised controlled trials through the systematic review

Table 2 Quality measures of randomised controlled trials that failed to fulfil any one of the markers of validity

\begin{tabular}{|c|c|c|c|c|c|c|}
\hline Trials & Concealment of randomisation & $\begin{array}{l}\text { Trial stopped } \\
\text { early }\end{array}$ & Patients blinded & Healthcare providers blinded & $\begin{array}{l}\text { Data collectors } \\
\text { blinded }\end{array}$ & $\begin{array}{l}\text { Outcome assessors } \\
\text { blinded }\end{array}$ \\
\hline$\overline{\text { Liu }^{19}}$ & No & No & Yes & Yes & Yes & Yes \\
\hline Stone $^{22}$ & Yes & No & No & Yes & Yes & Yes \\
\hline Poldermans ${ }^{33}$ & Yes & Yes & No & No & No & Yes \\
\hline Zaugg $^{35}$ & Yes & No & No & No & Yes & Yes \\
\hline $\operatorname{Urban}^{36}$ & Yes & Yes & No & No, except anaesthesiologists & Yes & Yes \\
\hline
\end{tabular}


Table 3 Effect of perioperative $\beta$ blockers within the first 30 days after non-cardiac surgery

\begin{tabular}{|c|c|c|c|c|c|c|}
\hline Outcome and trials & $\beta$ blocker groups & Control groups & Risk reduction & $\mathbf{9 5} \%$ confidence interval & $\mathbf{9 9} \%$ confidence interval & $1^{2}$ \\
\hline \multicolumn{7}{|l|}{ Total mortality } \\
\hline Wallace $^{31}$ & $4 / 99$ & $2 / 101$ & 2.04 & 0.38 to 10.89 & 0.23 to 18.43 & \\
\hline Bayliff $f^{32}$ & $2 / 49$ & $1 / 50$ & 2.04 & 0.19 to 21.79 & 0.09 to 45.85 & \\
\hline Poldermans $s^{33}$ & $2 / 59$ & $9 / 53$ & 0.20 & 0.05 to 0.88 & 0.03 to 1.41 & \\
\hline Yang $^{37}$ & $1 / 246$ & $7 / 250$ & 0.15 & 0.02 to 1.17 & 0.01 to 2.26 & \\
\hline Total & $9 / 453$ & $19 / 454$ & 0.56 & 0.14 to 2.31 & 0.09 to 3.60 & $57 \%$ \\
\hline \multicolumn{7}{|c|}{ Cardiovascular mortality } \\
\hline Wallace $^{31}$ & $1 / 99$ & $2 / 101$ & 0.51 & 0.05 to 5.54 & 0.02 to 11.71 & \\
\hline$\overline{\text { Bayliff }}{ }^{32}$ & $2 / 49$ & $1 / 50$ & 2.04 & 0.19 to 21.79 & 0.09 to 45.85 & \\
\hline Poldermans ${ }^{33}$ & $2 / 59$ & $9 / 53$ & 0.20 & 0.05 to 0.88 & 0.03 to 1.41 & \\
\hline Yang $^{37}$ & $0 / 246$ & $1 / 250$ & 0.34 & 0.01 to 8.27 & 0.01 to 22.59 & \\
\hline Total & $5 / 453$ & $13 / 454$ & 0.40 & 0.14 to 1.15 & 0.10 to 1.60 & $0 \%$ \\
\hline \multicolumn{7}{|c|}{ Non-fatal myocardial infarction } \\
\hline Jakobsen $^{30}$ & $1 / 18$ & $0 / 18$ & 3.00 & 0.13 to 69.09 & 0.05 to 185.13 & \\
\hline Poldermans ${ }^{33}$ & $0 / 59$ & $9 / 53$ & 0.05 & 0.00 to 0.79 & 0.00 to 1.93 & \\
\hline Raby $^{34}$ & $0 / 15$ & $1 / 11$ & 0.25 & 0.01 to 5.62 & 0.00 to 14.93 & \\
\hline Zaugg $^{35}$ & $0 / 43$ & $3 / 20$ & 0.07 & 0.00 to 1.26 & 0.00 to 3.15 & \\
\hline Urban $^{36}$ & $1 / 60$ & $3 / 60$ & 0.33 & 0.04 to 3.11 & 0.02 to 6.29 & \\
\hline$\overline{\text { Yang }^{37}}$ & $19 / 246$ & $21 / 250$ & 0.92 & 0.51 to 1.67 & 0.42 to 2.01 & \\
\hline Total & $21 / 441$ & $37 / 412$ & 0.38 & 0.11 to 1.29 & 0.08 to 1.88 & $45 \%$ \\
\hline \multicolumn{7}{|c|}{ Non-fatal cardiac arrest } \\
\hline Wallace $^{31}$ & $2 / 99$ & $3 / 101$ & 0.68 & 0.12 to 3.98 & 0.07 to 6.94 & \\
\hline$\overline{\text { Bayliff }}{ }^{32}$ & $0 / 49$ & $2 / 50$ & 0.20 & 0.01 to 4.14 & 0.00 to 10.67 & \\
\hline Total & $2 / 148$ & $5 / 151$ & 0.50 & 0.11 to 2.29 & 0.07 to 3.70 & $0 \%$ \\
\hline \multicolumn{7}{|c|}{$\begin{array}{l}\text { Major perioperative } \\
\text { cardiovascular events* }\end{array}$} \\
\hline Jakobsen $^{30}$ & $1 / 18$ & $0 / 18$ & 3.00 & 0.13 to 69.09 & 0.05 to 185.13 & \\
\hline$\overline{\text { Wallace }^{31}}$ & $3 / 99$ & $5 / 101$ & 0.61 & 0.15 to 2.49 & 0.10 to 3.88 & \\
\hline$\overline{\text { Bayliff }}{ }^{32}$ & $2 / 49$ & $3 / 50$ & 0.68 & 0.12 to 3.90 & 0.07 to 6.74 & \\
\hline Poldermans ${ }^{33}$ & $2 / 59$ & $18 / 53$ & 0.10 & 0.02 to 0.41 & 0.02 to 0.64 & \\
\hline Raby $^{34}$ & $0 / 15$ & $1 / 11$ & 0.25 & 0.01 to 5.62 & 0.00 to 14.93 & \\
\hline Zaugg $^{35}$ & $0 / 43$ & $3 / 20$ & 0.07 & 0.00 to 1.26 & 0.00 to 3.15 & \\
\hline $\operatorname{Urban}^{36}$ & $1 / 60$ & $3 / 60$ & 0.33 & 0.04 to 3.11 & 0.02 to 6.29 & \\
\hline Yang $^{37}$ & $19 / 246$ & $22 / 250$ & 0.88 & 0.49 to 1.58 & 0.41 to 1.90 & \\
\hline Total & $28 / 589$ & $55 / 563$ & 0.44 & 0.20 to 0.97 & 0.16 to 1.24 & $42 \%$ \\
\hline \multicolumn{7}{|l|}{ Non-fatal stroke } \\
\hline Wallace ${ }^{31}$ & $4 / 99$ & $1 / 101$ & 4.08 & 0.46 to 35.87 & 0.23 to 71.02 & NA \\
\hline \multicolumn{7}{|c|}{ Congestive heart failure } \\
\hline Magnusson $^{20}$ & $0 / 15$ & $1 / 15$ & 0.33 & 0.01 to 7.58 & 0.01 to 20.25 & \\
\hline Jakobsen $^{30}$ & $1 / 18$ & $0 / 18$ & 3.00 & 0.13 to 69.09 & 0.05 to 185.13 & \\
\hline Wallace $^{31}$ & 9/99 & $7 / 101$ & 1.31 & 0.51 to 3.38 & 0.38 to 4.56 & \\
\hline$\overline{\text { Bayliff }} \mathrm{f}^{32}$ & $8 / 49$ & $4 / 50$ & 2.04 & 0.66 to 6.34 & 0.46 to 9.05 & \\
\hline Yang $^{37}$ & $5 / 246$ & $3 / 250$ & 1.69 & 0.41 to 7.01 & 0.26 to 10.96 & \\
\hline Total & $23 / 427$ & $15 / 434$ & 1.54 & 0.83 to 2.87 & 0.68 to 3.48 & $0 \%$ \\
\hline \multicolumn{7}{|c|}{ Hypotension needing treatment } \\
\hline Colman $^{16}$ & $1 / 27$ & $0 / 15$ & 1.71 & 0.07 to 39.65 & 0.03 to 106.39 & \\
\hline Cucchiara $^{17}$ & $5 / 37$ & $5 / 37$ & 1.00 & 0.32 to 3.17 & 0.22 to 4.55 & \\
\hline Gibson $^{21}$ & $1 / 21$ & $0 / 19$ & 2.73 & 0.12 to 63.19 & 0.04 to 169.63 & \\
\hline$\overline{\text { Stone }^{22}}$ & $12 / 89$ & $2 / 39$ & 2.63 & 0.62 to 11.20 & 0.39 to 17.65 & \\
\hline$\overline{\text { Miller }^{27}}$ & $1 / 30$ & $0 / 15$ & 1.55 & 0.07 to 35.89 & 0.02 to 96.36 & \\
\hline Miller $^{28}$ & $39 / 368$ & $19 / 180$ & 1.00 & 0.60 to 1.69 & 0.51 to 1.98 & \\
\hline$\overline{\text { Davies }^{29}}$ & $6 / 20$ & $11 / 20$ & 0.55 & 0.25 to 1.19 & 0.20 to 1.52 & \\
\hline$\overline{\text { Wallace }^{31}}$ & $13 / 99$ & $13 / 101$ & 1.02 & 0.50 to 2.09 & 0.40 to 2.62 & \\
\hline$\overline{\text { Bayliff }} \mathrm{f}^{32}$ & $24 / 49$ & $13 / 50$ & 1.88 & 1.09 to 3.26 & 0.92 to 3.87 & \\
\hline Yang $^{37}$ & $114 / 246$ & $84 / 250$ & 1.38 & 1.11 to 1.72 & 1.03 to 1.84 & \\
\hline Total & $216 / 986$ & $147 / 726$ & 1.27 & 1.04 to 1.56 & 0.97 to 1.66 & $6 \%$ \\
\hline \multicolumn{7}{|c|}{ Bradycardia needing treatment } \\
\hline Cucchiara $^{17}$ & $0 / 37$ & $1 / 37$ & 0.33 & 0.01 to 7.93 & 0.01 to 21.46 & \\
\hline$\overline{\mathrm{Liu}^{19}}$ & $0 / 16$ & $1 / 14$ & 0.29 & 0.01 to 6.69 & 0.00 to 17.86 & \\
\hline$\overline{\text { Magnusson }}{ }^{20}$ & $4 / 15$ & $0 / 15$ & 9.00 & 0.53 to 153.79 & 0.22 to 375.21 & \\
\hline Stone $^{22}$ & $10 / 89$ & $0 / 39$ & 9.33 & 0.56 to 155.41 & 0.23 to 376.09 & \\
\hline$\overline{\text { McKenzie }^{23}}$ & $1 / 50$ & $0 / 50$ & 3.00 & 0.13 to 71.92 & 0.05 to 195.17 & \\
\hline Jakobsen $^{26}$ & $5 / 49$ & $1 / 49$ & 5.00 & 0.61 to 41.25 & 0.31 to 80.06 & \\
\hline$\overline{\text { Davies }^{29}}$ & $12 / 20$ & $8 / 20$ & 1.50 & 0.79 to 2.86 & 0.64 to 3.50 & \\
\hline Wallace $^{31}$ & $2 / 99$ & $1 / 101$ & 2.04 & 0.19 to 22.14 & 0.09 to 46.84 & \\
\hline
\end{tabular}




\begin{tabular}{|c|c|c|c|c|c|c|}
\hline Outcome and trials & $\beta$ blocker groups & Control groups & Risk reduction & $95 \%$ confidence interval & $\mathbf{9 9} \%$ confidence interval & $1^{2}$ \\
\hline Yang $^{37}$ & $53 / 246$ & $19 / 250$ & 2.83 & 1.73 to 4.64 & 1.48 to 5.42 & \\
\hline Total & $87 / 621$ & $31 / 575$ & 2.27 & 1.53 to 3.36 & 1.36 to 3.80 & $3 \%$ \\
\hline \multicolumn{7}{|l|}{ Bronchospasm } \\
\hline Cucchiara $^{17}$ & $1 / 37$ & $0 / 37$ & 3.00 & 0.13 to 71.34 & 0.05 to 193.10 & \\
\hline Jakobsen $^{18}$ & $1 / 10$ & $0 / 10$ & 3.00 & 0.14 to 65.90 & 0.05 to 173.99 & \\
\hline MacKenzie $^{23}$ & $0 / 50$ & $1 / 50$ & 0.33 & 0.01 to 7.99 & 0.01 to 21.69 & \\
\hline $\operatorname{lnada}^{24}$ & $1 / 20$ & $1 / 10$ & 0.50 & 0.03 to 7.19 & 0.02 to 16.62 & \\
\hline Leslie $^{25}$ & $1 / 40$ & $2 / 20$ & 0.25 & 0.02 to 2.59 & 0.01 to 5.41 & \\
\hline Jakobsen $^{26}$ & $1 / 49$ & $1 / 49$ & 1.00 & 0.06 to 15.54 & 0.03 to 36.80 & \\
\hline$\overline{\text { Miller }^{28}}$ & $4 / 368$ & $2 / 180$ & 0.98 & 0.18 to 5.29 & 0.11 to 8.99 & \\
\hline Jakobsen $^{30}$ & $1 / 18$ & $1 / 18$ & 1.00 & 0.07 to 14.79 & 0.03 to 34.47 & \\
\hline Wallace $^{31}$ & $3 / 99$ & 0/101 & 7.14 & 0.37 to 136.46 & 0.15 to 344.84 & \\
\hline Bayliff $^{32}$ & $12 / 49$ & $16 / 50$ & 0.77 & 0.41 to 1.45 & 0.33 to 1.77 & \\
\hline Yang $^{37}$ & $4 / 246$ & $1 / 250$ & 4.07 & 0.46 to 36.11 & 0.23 to 71.74 & \\
\hline Total & $29 / 986$ & $25 / 775$ & 0.91 & 0.55 to 1.50 & 0.47 to 1.75 & $0 \%$ \\
\hline
\end{tabular}

NA=not applicable.

${ }^{*}$ Composite outcome of cardiovascular death, non-fatal myocardial infarction, and non-fatal cardiac arrest.

\section{Discussion}

Our results suggest that perioperative $\beta$ blockers may decrease the risk of major perioperative cardiovascular events but increase the risk of bradycardia and hypotension needing treatment. These results, however, are based on only a moderate number of major perioperative cardiovascular events and patients with bradycardia needing treatment. A total of 1152 patients were randomised in the eight trials that had patients who had a major perioperative cardiovascular event. This number of patients randomised is much smaller than our calculated optimal information size (6124 patients, based on the $10 \%$ event rate in current trials) needed to reliably detect a plausible treatment effect of $\beta$ blocker treatment in patients having non-cardiac surgery. Our use of methods adapted from formal interim monitoring boundaries applied to cumulative meta-analysis showed that

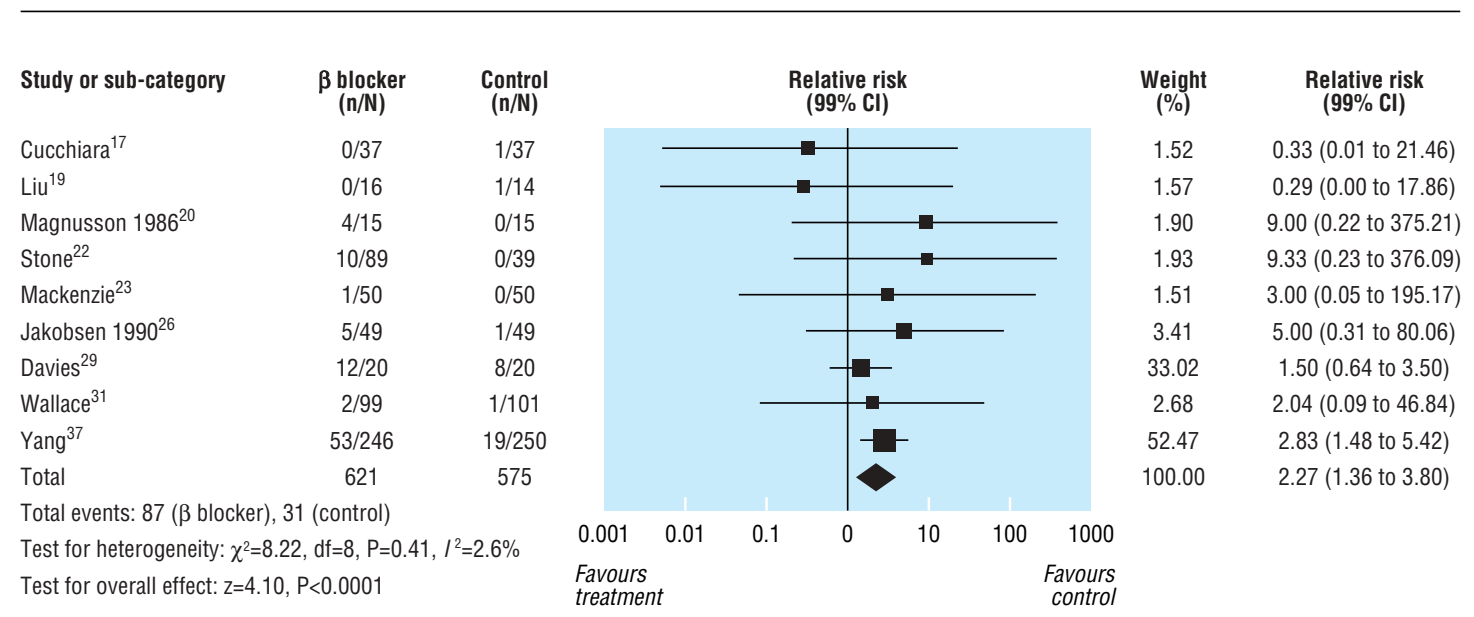

Fig 2 Relative risks for bradycardia needing treatment

\begin{tabular}{|c|c|c|c|c|c|c|c|c|c|c|c|c|}
\hline Study or sub-category & $\begin{array}{c}\beta \text { blocker } \\
(\mathrm{n} / \mathrm{N})\end{array}$ & \multirow{2}{*}{$\begin{array}{c}\begin{array}{c}\text { Control } \\
(\mathbf{n} / \mathbf{N})\end{array} \\
0 / 18\end{array}$} & & \multicolumn{6}{|c|}{$\begin{array}{c}\text { Relative risk } \\
(99 \% \text { Cl) }\end{array}$} & & \multirow{2}{*}{$\begin{array}{c}\text { Weight } \\
\text { (\%) } \\
5.29\end{array}$} & \multirow{2}{*}{$\begin{array}{c}\begin{array}{c}\text { Relative risk } \\
(99 \% \mathrm{Cl})\end{array} \\
3.00(0.05 \text { to } 185.13)\end{array}$} \\
\hline Jakobsen $1997^{30}$ & $1 / 18$ & & & & & & \multicolumn{3}{|c|}{$\square$} & & & \\
\hline Wallace ${ }^{31}$ & $3 / 99$ & $5 / 101$ & & & & & & & & & 16.38 & $0.61(0.10$ to 3.88$)$ \\
\hline Bayliff $^{32}$ & $2 / 49$ & $3 / 50$ & & & & & & & & & 12.74 & $0.68(0.07$ to 6.74$)$ \\
\hline Poldermans $^{33}$ & 2/59 & $18 / 53$ & & & $\rightarrow$ & & & & & & 16.27 & $0.10(0.02$ to 0.64$)$ \\
\hline Raby $^{34}$ & 0/15 & $1 / 11$ & & & & & & & & & 5.36 & $0.25(0.00$ to 14.93$)$ \\
\hline Zaugg $^{35}$ & $0 / 43$ & $3 / 20$ & & & & & & & & & 5.98 & $0.07(0.00$ to 3.15$)$ \\
\hline$U_{r b a n}^{36}$ & $1 / 60$ & $3 / 60$ & & & & & & & & & 9.08 & $0.33(0.02$ to 6.29$)$ \\
\hline Yang $^{37}$ & $19 / 246$ & $22 / 250$ & & & & & & & & & 28.90 & 0.88 (0.41 to 1.90$)$ \\
\hline Total & 589 & 563 & & & & & & & & & 100.00 & $0.44(0.16$ to 1.24$)$ \\
\hline \multicolumn{3}{|c|}{ Total events: 28 ( $\beta$ blocker), 55 (control) } & & & & & & & & & & \\
\hline \multicolumn{3}{|c|}{ Test for heterogeneity: $\chi^{2}=12.07, \mathrm{df}=7, \mathrm{P}=0.10, I^{2}=42.0 \%$} & 0.001 & 0.01 & 0.1 & & & 10 & 100 & 1000 & & \\
\hline \multicolumn{3}{|c|}{ Test for overall effect: $z=2.05, P=0.04$} & $\begin{array}{l}\text { Favour } \\
\text { treatm }\end{array}$ & & & & & & & $\begin{array}{l}\text { Favours } \\
\text { control }\end{array}$ & & \\
\hline
\end{tabular}

Fig 3 Relative risks for major perioperative cardiovascular events (cardiovascular death, non-fatal myocardial infarction, or non-fatal cardiac arrest) 


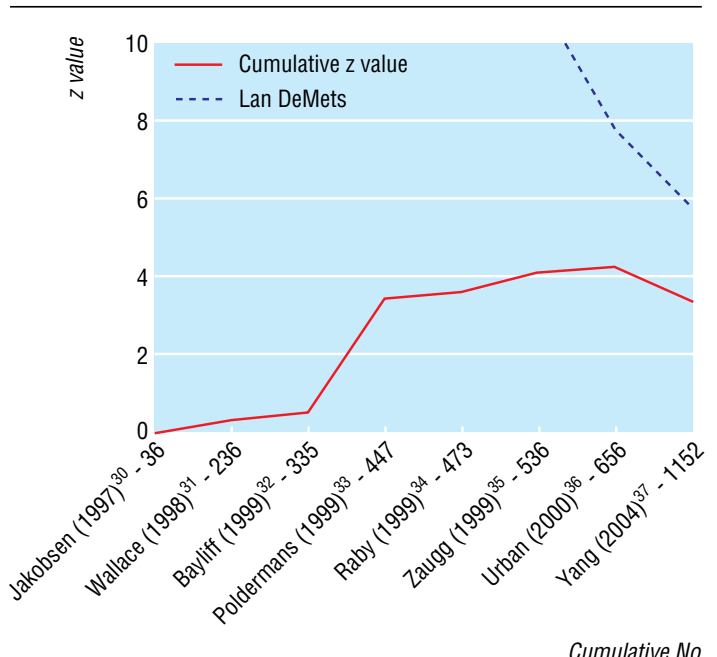

Fig 4 Cumulative meta-analysis assessing the effect of perioperative $\beta$ blockers on the 30 day risk of major perioperative cardiovascular events (cardiovascular death, non-fatal myocardial infarction, or non-fatal cardiac arrest) in patients having non-cardiac surgery. The Lan-DeMets sequential monitoring boundary, which assumes a $10 \%$ control event rate and a $25 \%$ relative risk reduction with $80 \%$ power and a two sided $\alpha=0.01$, has not been crossed, indicating that the cumulative evidence is inconclusive

the current evidence for perioperative $\beta$ blocker is insufficient and inconclusive.

\section{Strengths and weaknesses}

Our systematic review has several strengths. We did a comprehensive search using seven strategies to identify randomised controlled trials, conducted eligibility decisions and data abstraction in duplicate and showed a high degree of agreement, obtained data from or confirmed them with all trialists, and evaluated the reliability and conclusiveness of the available evidence on perioperative $\beta$ blockers through a method adapted from formal interim monitoring boundaries applied to cumulative meta-analysis.

Our systematic review focuses only on short term outcomes (within 30 days of surgery). It is possible that perioperative $\beta$ blockers affect long term cardiovascular outcomes. Of all the randomised controlled trials we identified, only the trial by Mangano et al evaluated the effect of perioperative $\beta$ blocker treatment on long term outcomes. ${ }^{39}$ This trial is the long term follow-up component of the trial by Wallace et al that is included in our review. The authors reported 30 deaths during the two year follow-up among the 200 patients randomised to atenolol or placebo for a maximum of seven postoperative days and a greater than $50 \%$ reduction in the relative risk of death among patients who received atenolol. ${ }^{39}$ These results, however, did not include the six deaths that occurred during the period when patients were receiving the study drug. When these events are appropriately included in the intention to treat analysis the reduction in the risk of death with atenolol is no longer statistically significant. $^{10}$

\section{Relation to other systematic reviews}

A systematic review by Auerbach and Goldman and a systematic review and meta-analysis by Stevens et al have evaluated the effects of perioperative $\beta$ blockers. ${ }^{40}{ }^{41}$ The main difference between our systematic reviews is that we included a lot more trials and we used methods adapted from formal interim monitoring boundaries applied to cumulative meta-analysis to determine if the current evidence is reliable and conclusive.

\section{Implications}

Our systematic review provides encouraging evidence that perioperative $\beta$ blockers may reduce the risk of major perioperative cardiovascular events but increase the risk of bradycardia and hypotension needing treatment in patients having non-cardiac surgery. Using a subset of the evidence we identified, several authors and the American College of Cardiology/American Heart Association guidelines have recommended perioperative $\beta$ blocker treatment for varying groups of patients having non-cardiac surgery. ${ }^{5-8} 42$ These recommendations warrant cautious interpretation.

Firstly, only a moderate number of events occurred in the perioperative $\beta$ blocker trials (for example, 83 major perioperative cardiovascular events). Secondly, the evidence on perioperative $\beta$ blockers from our meta-analyses suggests a large treatment effect $(56 \%$ relative risk reduction in major perioperative cardiovascular events). This treatment effect, however, is inconsistent with the results of the $\beta$ blocker trials in myocardial infarction and congestive heart failure that have randomised more than 50000 patients and have shown moderate treatment effects (relative risk reductions of $15-35 \%$ ). ${ }^{38-46}$ If perioperative $\beta$ blockers prevent major perioperative cardiovascular events, they probably do so through suppressing adrenergic activity. Therefore, large treatment effects are unlikely, because a substantial number of perioperative cardiovascular pathogenic mechanisms that $\beta$ blockers do not affect remain (increased platelet reactivity, plasminogen activator inhibitor I, factor VIII related antigen levels, and inflammation; decreased antithrombin III concentrations). ${ }^{47-50}$

Thirdly, the nominally statistically significant beneficial result of decreased major perioperative cardiovascular events with $\beta$ blocker treatment showed moderate heterogeneity $\left(\mathrm{I}^{2}=42 \%\right)$, which weakens the reliability of this finding. Furthermore, the relative risk estimate from the three trials with methodological limitations (stopped early for unexpected large treatment effects or failure to blind) was sixfold lower than that of the high quality trials that failed to show a statistically significant result. This finding is in contrast to the outcomes of bradycardia and hypotension needing treatment, which showed low heterogeneity, strengthening the reliability of these findings.

Fourthly, for a meta-analysis to provide definitive evidence it should fulfil at least the minimum standards expected of a well designed, adequately powered, and rigorously conducted single randomised controlled trial. In fact, the potential for additional biases (such as publication bias), heterogeneity in various features of the design and conduct of the included trials, and an inflated type I error rate (due to multiple looks at the data as trials are added) suggest that a higher level of scepticism is appropriate in interpreting a meta-analysis than a single randomised controlled trial. The question of whether a meta-analysis is definitive can be considered by using the logic of early stopping for a randomised controlled trial. The analogy to early stopping of a single trial would be a recommendation, on the basis of a meta-analysis, to stop doing further trials. Using this logic, criteria can be adduced for concluding that evidence is adequate to recommend that no further studies are needed.

Our calculated optimal information size needed to reliably detect a plausible treatment effect was 6124 patients, assuming a $10 \%$ event rate-with a lower event rate, which is more probable, a higher optimal information size is needed. Our meta-analysis, however, showed that the eight trials that had patients who had a major perioperative cardiovascular event included only $20 \%$ of this minimal sample size. Using the optimal information size we constructed a sequential monitoring boundary, and the cumula- 


\section{What is already known on this topic}

Several authors and guidelines committees have advocated the use of $\beta$ blockers in patients having non-cardiac surgery

The robustness of the evidence for this intervention has been questioned

\section{What this study adds}

Perioperative $\beta$ blockers may decrease the risk of major perioperative cardiovascular events but increase the risk of bradycardia and hypotension needing treatment

The beneficial results, however, are based on only a moderate number of major events, and the findings depend on methodologically weak trials

Methods adapted from formal interim monitoring boundaries applied to cumulative meta-analysis show that the evidence for perioperative $\beta$ blockers is insufficient and inconclusive

tive meta-analysis has not crossed this monitoring boundary. If the data included in our meta-analysis were from a single randomised controlled trial at an interim analysis, insufficient evidence would exist to justify stopping the trial. The monitoring boundary therefore indicates that the cumulative evidence is inconclusive and further research is needed.

The evidence examined in our systematic review identifies the need and provides the impetus for a large adequately powered randomised controlled trial on perioperative $\beta$ blockers to definitively establish the benefits and risks of such treatment. Such a trial, the perioperative ischemic evaluation (POISE) trial, which plans to recruit 10000 patients, was recently initiated and has recruited more than 4000 patients in 18 countries to date. Clear evidence establishing the role of $\beta$ blockers in patients having non-cardiac surgery awaits the results of such trials.

We thank all the authors of the randomised controlled trials of $\beta$ blockers who confirmed and provided data related to their trials.

Contributors: PJD contributed to the concept and design, data acquisition, data analysis, and interpretation of the data; wrote the first draft of the manuscript; critically revised the manuscript; and gave final approval of the submitted manuscript. WSB, PT-LC, NHB, VMM, and C-IJ contributed to the concept and design, data acquisition, and interpretation of data; critically revised the manuscript; and gave final approval of the submitted manuscript. VMM contributed to the concept and design, data analysis, and interpretation of data; critically revised the manuscript; and gave final approval of the submitted manuscript. GHG, JCV, CSC, KL, MJJ, MB, AA, ABC, JWG, TS, HY, and SY contributed to the concept and design and interpretation of the data; critically revised the manuscript; and gave final approval of the submitted manuscript. PJD is the guarantor.

Funding: PJD is supported by a Canadian Institutes of Health Research senior research fellowship award. WSB is the R Fraser Elliot Chair of Cardiac Anesthesia and is supported by the Toronto General and Western Foundations and the University Health Network, University of Toronto. PT-LC is supported by a Vancouver Coastal Health Research Institute mentored clinician scientist award. JCV is supported by a Heart and Stroke Foundation of Canada doctoral research award. VMM is a Mayo Foundation scholar. MB is supported by the Detweiler Fellowship from the Royal College of Physicians and Surgeons of Canada, and a Department of Clinical Epidemiology and Biostatistics, McMaster University, clinical scientist fellowship award. JWG is supported by a Department of Anesthesia, Oxford University, research fellowship award. SY holds an endowed chair of the Heart and Stroke Foundation of Ontario and is a senior scientist of the Canadian Institutes of Health Research.

Competing interests: PJD, WSB, PT-LC, NHB, GHG, JCV, CSC, KL, MJJ, VMM, AA, ABC, JWG, TS, HY, and SY are all members of the POISE trial.
SY has received honorariums and research grants from AstraZeneca, which manufactures metoprolol CR.

1 Sametz W, Metzler H, Gries M, Porta S, Sadjak A, Supanz S, et al. Perioperative catecholamine changes in cardiac risk patients. Eur J Clin Invest 1999;29:582-7.

2 Parker SD, Breslow MJ, Frank SM, Rosenfeld BA, Norris EJ, Christopherson R, et al Catecholamine and cortisol responses to lower extremity revascularization: correlation with outcome variables. Crit Care Med 1995;23:1954-61.

3 Priebe HJ. Triggers of perioperative myocardial ischaemia and infarction. Br J Anaesth 2004;93:9-20.

Weissman C. The metabolic response to stress: an overview and update. Anesthesiology 1990;73:308-27.

5 Lee TH. Reducing cardiac risk in noncardiac surgery. N Engl J Med 1999;341:1838-40.

6 Grayburn PA, Hillis LD. Cardiac events in patients undergoing noncardiac surgery: shifting the paradigm from noninvasive risk stratification to therapy. Ann Intern Med 2003:138:506-11.

7 Palda VA, Detsky AS. Perioperative assessment and management of risk from coronary artery disease. Ann Intern Med 1997;127:313-28.

8 Eagle KA, Berger PB, Calkins H, Chaitman BR, Ewy GA, Fleischmann KE, et al. ACC/ AHA guideline update for perioperative cardiovascular evaluation for noncardiac surgery-executive summary: a report of the American College of Cardiology/ American Heart Association Task Force on Practice Guidelines (Committee to Update the 1996 Guidelines on Perioperative Cardiovascular Evaluation for Noncardiac Surgery).J Am Coll Cardiol 2002;39:542-53.

9 Jacka MJ, Schricker T, Warriner B, Boulton A, Hudson R. More conclusive large-scale trials necessary before recommending use of beta blockade in patients at risk. Anesth Analg 2004;98:269, author reply 269-70.

10 Swedberg K, Wedel H. Effect of atenolol on mortality and cardiovascular morbidity after noncardiac surgery. Evidence-Based Cardiovascular Medicine 1998;2:33.

11 Pogue J, Yusuf S. Overcoming the limitations of current meta-analysis of randomised controlled trials. Lancet 1998;351:47-52.

12 Whitehead A, Whitehead J. A general parametric approach to the meta-analysis of randomized clinical trials. Stat Med 1991;10:1665-77.

13 DerSimonian R, Laird N. Meta-analysis in clinical trials. Control Clin Trials 1986;7:17788.

14 Higgins JP, Thompson SG, Deeks JJ, Altman DG. Measuring inconsistency in meta-analyses. $B M J$ 2003;327:557-60.

15 Pogue JM, Yusuf S. Cumulating evidence from randomized trials: utilizing sequential monitoring boundaries for cumulative meta-analysis. Control Clin Trials 1997;18:58093, discussion 661-6.

16 Coleman AJ, Jordan C. Cardiovascular responses to anaesthesia: influence of beta-adrenoreceptor blockade with metoprolol. Anaesthesia 1980;35:972-8.

17 Cucchiara RF, Benefiel DJ, Matteo RS, DeWood M, Albin MS. Evaluation of esmolol in controlling increases in heart rate and blood pressure during endotracheal intubation in patients undergoing carotid endarterectomy. Anesthesiology 1986;65:528-31.

18 Jakobsen CJ, Grabe N, Christensen B. Metoprolol decreases the amount of halothane required to induce hypotension during general anaesthesia. $\mathrm{Br} J$ Anaesth 1986;58:261-6.

19 Liu PL, Gatt S, Gugino LD, Mallampati SR, Covino BG. Esmolol for control of increases in heart rate and blood pressure during tracheal intubation after thiopentone and succinylcholine. Can Anaesth Soc J 1986;33:556-62.

20 Magnusson J, Thulin T, Werner O, Jarhult J, Thomson D. Haemodynamic effects of pretreatment with metoprolol in hypertensive patients undergoing surgery. Br J Anaesth 1986;58:251-60

21 Gibson BE, Black S, Maass L, Cucchiara RF. Esmolol for the control of hypertension after neurologic surgery. Clin Pharmacol Ther 1988;44:650-3.

22 Stone JG, Foex P, Sear JW, Johnson LL, Khambatta HJ, Triner L. Myocardial ischemia in untreated hypertensive patients: effect of a single small oral dose of a beta-adrenergic blocking agent. Anesthesiology 1988;68:495-500.

23 Mackenzie JW, Bird J. Timolol: a non-sedative anxiolytic premedicant for day cases. BMJ 1989;298:363-4.

24 Inada E, Cullen DJ, Nemeskal AR, Teplick R. Effect of labetalol or lidocaine on the hemodynamic response to intubation: a controlled randomized double-blind study. J Clin Anesth 1989;1:207-13.

25 Leslie JB, Kalayjian RW, McLoughlin TM, Plachetka JR. Attenuation of the hemodynamic responses to endotracheal intubation with preinduction intravenous labetalol.J Clin Anesth 1989;1:194-200.

26 Jakobsen CJ, Blom L, Brondbjerg M, Lenler-Petersen P. Effect of metoprolol and diazepam on pre-operative anxiety. Anaesthesia 1990;45:40-3.

27 Miller D, Martineau R, Hull K, Hill J. Bolus administration of esmolol for controlling the hemodynamic response to laryngoscopy and intubation: efficacy and effects on myocardial performance. J Cardiothorac Anesth 1990;4:31-6.

28 Miller DR, Martineau RJ, Wynands JE, Hill J. Bolus administration of esmolol for controlling the haemodynamic response to tracheal intubation: the Canadian multicentre trolling the haemodynamic response
trial. Can J Anaesth 1991;38:849-58.

99 Davies MJ, Dysart RH, Silbert BS, Scott DA, Cook RJ. Prevention of tachycardia with atenolol pretreatment for carotid endarterectomy under cervical plexus blockade Anaesth Intensive Care 1992;20:161-4

30 Jakobsen CJ, Bille S, Ahlburg P, Rybro L, Pedersen KD, Rasmussen B. Preoperative metoprolol improves cardiovascular stability and reduces oxygen consumption after thoracotomy. Acta Anaesthesiol Scand 1997;41:1324-30.

31 Wallace A, Layug B, Tateo I, Li J, Hollenberg M, Browner W, et al. Prophylactic atenolol reduces postoperative myocardial ischemia. Anesthesiology 1998;88:7-17.

32 Bayliff CD, Massel DR, Inculet RI, Malthaner RA, Quinton SD, Powell FS, et al. Propranolol for the prevention of postoperative arrhythmias in general thoracic surgery. Ann Thorac Surg 1999;67:182-6.

33 Poldermans D, Boersma E, Bax IJ, Thomson IR, van de Ven LL, Blankensteijn JD, et al. The effect of bisoprolol on perioperative mortality and myocardial infarction in highThe effect of bisoprolol on perioperative mortality and myocardial infarction
risk patients undergoing vascular surgery. $N$ Engl J Med 1999:341:1789-94.

34 Raby KE, Brull SJ, Timimi F, Akhtar S, Rosenbaum S, Naimi C, et al. The effect of heart rate control on myocardial ischemia among high-risk patients after vascular surgery. Anesth Analg 1999;88:477-82 
35 Zaugg M, Tagliente T, Lucchinetti E, Jacobs E, Krol M, Bodian C, et al. Beneficial effects from beta-adrenergic blockade in elderly patients undergoing noncardiac surgery. Anesthesiology 1999;91:1674-86.

36 Urban MK, Markowitz SM, Gordon MA, Urquhart BL, Kligfield P. Postoperative prophylactic administration of beta-adrenergic blockers in patients at risk for myocardial ischemia. Anesth Analg 2000;90:1257-61.

37 Yang H, Raymer K, Butler R, Parlow J, Roberts R. Metoprolol after vascular surgery (MaVS). Can J Anesth 2004;51:A7.

38 Yusuf S, Peto R, Lewis J, Collins R, Sleight P. Beta blockade during and after myocardial infarction: an overview of the randomized trials. Prog Cardiovasc Dis 1985;27.335-71.

39 Mangano DT, Layug EL, Wallace A, Tateo I. Effect of atenolol on mortality and cardiovascular morbidity after noncardiac surgery. N Engl J Med 1996;335:1713-20.

40 Auerbach AD, Goldman L. Beta-blockers and reduction of cardiac events in noncardiac surgery: scientific review. JAMA 2002;287:1435-44.

41 Stevens RD, Burri H, Tramer MR. Pharmacologic myocardial protection in patients undergoing noncardiac surgery: a quantitative systematic review. Anesth Analg 2003;97:623-33

42 Butterworth J, Furberg CD. Improving cardiac outcomes after noncardiac surgery. Anesth Analg 2003;97:613-5.

43 First International Study of Infarct Survival Collaborative Group. Randomised trial of intravenous atenolol among 16027 cases of suspected acute myocardial infarction: ISIS-1. Lancet 1986;2:57-66.

44 Lechat P, Packer M, Chalon S, Cucherat M, Arab T, Boissel JP. Clinical effects of beta-adrenergic blockade in chronic heart failure: a meta-analysis of double-blind, beta-adrenergic blockade in chronic heart failure: a meta-analysis
placebo-controlled, randomized trials. Circulation 1998;98:1184-91.

45 The cardiac insufficiency bisoprolol study II (CIBIS-II): a randomised trial. Lancet 1999;353:9-13.

46 Effect of metoprolol $\mathrm{CR} / \mathrm{XL}$ in chronic heart failure: metoprolol CR/XL randomised intervention trial in congestive heart failure (MERIT-HF). Lancet 1999;353:2001-7.

47 McDaniel MD, Pearce WH, Yao JS, Rossi EC, Fahey VA, Green D, et al. Sequential changes in coagulation and platelet function following femorotibial bypass.J Vasc Surg 1984;1:261-8.

48 Rosenfeld BA, Beattie C, Christopherson R, Norris EJ, Frank SM, Breslow MJ, et al. The effects of different anesthetic regimens on fibrinolysis and the development of postoperative arterial thrombosis. Anesthesiology 1993;79:435-43.

49 Schillinger M, Domanovits H, Bayegan K, Holzenbein T, Grabenwoger M, Thoenissen $\mathrm{J}$, et al. C-reactive protein and mortality in patients with acute aortic disease. Intensive

50 Flinn WR, McDaniel MD, Yao JS, Fahey VA, Green D. Antithrombin III deficiency as a reflection of dynamic protein metabolism in patients undergoing vascular reconstruction. J Vasc Surg 1984;1:888-95.

(Accepted 19 May 2005)

doi $10.1136 / \mathrm{bmj} .38503 .623646 .8 \mathrm{~F}$

Departments of Medicine and Clinical Epidemiology and Biostatistics, McMaster Departments of Medicine and Clinica

P J Devereaux assistant professor

Gordon H Guyatt professor
Department of Surgery and Clinical Epidemiology and Biostatistics, McMaster University

Claudio S Cinà associate professor

Mohit Bhandari assistant professor

Department of Medicine and Population Health Research Institute, McMaster University

Salim Yusuf professor

Department of Anesthesia, University of Toronto, Toronto, ON, Canada

W Scott Beattie associate professor

Vancouver Coastal Health Research Institute and Department of Anesthesia, University of British Columbia, Vancouver, BC, Canada

Peter T-L Choi assistant professor

Departments of Anesthesiology and Perioperative Medicine, University of Western Ontario, London, ON, Canada

Neal H Badner associate professor

Grupo de Cardiología Preventiva, Universidad Autonoma de Bucaramanga, Colombia

Juan C Villar assistant professor

Department of Anaesthesia and Pain Management, Royal Melbourne Hospital,

Melbourne, Australia

Kate Leslie associate professor

Departments of Anesthesiology and Critical Care, University of Alberta,

Edmonton, AB, Canada

Michael J Jacka assistant professor

Department of Medicine, Mayo Clinic College of Medicine, Rochester, MN, USA

Victor M Montori assistant professor

Dante Pazzanese Institute of Cardiology and the Albert Einstein Hospital, São

Paulo, Brazil

Alvaro Avezum research director

Alexandre B Cavalcanti intensivist

Nuffield Department of Anaesthetics, University of Oxford

Julian W Giles honorary research fellow

Department of Anesthesia, McGill University, Montreal, QC, Canada

Thomas Schricker assistant professor

Department of Anesthesia, University of Ottawa, Ottawa, ON, Canada

Homer Yang professor

Department of Anaesthesia and Intensive Care, Aarhus University Hospital,

Aarhus, Denmark

Carl-Johan Jakobsen associate professor

Correspondence to: PJ Devereaux philipj@mcmaster.ca 